\title{
An Assessment of the 100 Most Frequently Cited Articles Related to Bicuspid Aortic Valve in the Literature
}

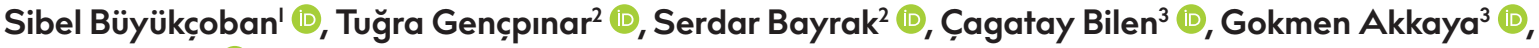 \\ Volkan Hanci' (1)
}

'Department of Anaesthesiology and Reanimation, Dokuz Eylül University School of Medicine, İzmir, Turkey ${ }^{2}$ Department of Cardiovascular Surgery, Dokuz Eylül University School of Medicine, İzmir, Turkey

${ }^{3}$ Department of Cardiovascular Surgery, Ege University School of Medicine, İzmir, Turkey

ORCID iDs of the authors: S.B. 0000-0002-5756-980X; T.G. 0000-0003-4438-799I; S.B. 0000-0003-I458-9023; C.B. 0000-0002-9I585627; G.A. 0000-0002-0509-197I; V.H. 0000-0002-2227-194X.

Cite this article as: Büyükçoban S, Gençpınar T, Bayrak S, Bilen Ç, Akkaya G, Hanci V. An Assessment of the I00 Most Frequently Cited Articles Related to Bicuspid Aortic Valve in the Literature. Cyprus J Med Sci 202l; 6(I): 54-66.

\section{BACKGROUND/AIMS}

Bicuspid aortic valve disease may cause both aortic stenosis and regurgitation; therefore, it manifests as different symptoms. Aortic stenosis in patients with bicuspid aortic valve exhibits ambiguous hemodynamic effects; moreover, it may remain asymptomatically until the effective orifice area is narrowed below $1.5-2 \mathrm{~cm}^{2}$. In this study, we aimed to evaluate 100 articles related to bicuspid aortic valve that have been most frequently cited in the literature.

\section{MATERIAL and METHODS}

The study was performed using advanced mode of the search engine server Institute for Scientific Information Web of Science. For this purpose, the words "TS=bicuspid or Tl=bicuspid" were reviewed. The search was carried out, and the 100 most cited articles were determined. The total and annual cite count for each article and information about the authors and the journals were determined via WOS and PubMed.

\section{RESULTS}

The mean cite count of the 100 most cited articles was found to be $238.10 \pm 227.48$. The annual cite counts of the studies varied from 4 to 185 , and the mean value was calculated as $20.93 \pm 25.25$. The first 3 subjects were clinical BAV ( $41 \%)$, pathology of BAV (I5\%), and genetics of BAV (15\%). There was no statistically significant difference between the continent of the corresponding author and overall and annual cite counts. In addition, no statistically significant difference was observed between the journal's continent and overall and annual cite counts ( $p>$.05).

\section{CONCLUSION}

This study is the first in the literature to identify the 100 most cited articles related to BAV. The majority of these studies were based on clinical evaluation of BAV. We found an increase in the number of studies on percutaneous transcatheter interventions over the last 5 years.

Keywords: Bicuspid aortic valve, bibliometrics, aortic aneurysm, aortic stenosis

\section{INTRODUCTION}

In the current era, several studies have been conducted by different international or national institutes and surgical disciplines to determine the most cited articles for medical sciences $(\mid-4)$. When a scientific paper references another scientific paper, it is identified as "cited." The scientific articles that had been a resource of or that strengthened the findings are accepted as cited if they are referred in any part of another scientific paper. The impact factor of the article is evaluated according to the frequency of citation. The more cited articles and the journals with a higher impact factor are considered more qualified $(5,6)$.

The first bibliographic study on the 100 Citation Classics From the Journal of the American Medical Association published in the Journal of the American Medical Association was written by Garfield et al. (5). Since then, numerous stud- 
ies investigating the most cited articles have been presented not only in general medical journals but also in specialized journals (7). For example, Ahmad et al. (8) presented the 100 most cited articles on bariatric surgery between 1945 and 2014, and Amina et al. (9) reported the 50 most frequently cited articles on bariatric and endocrinological surgery published between 1950 and 2000.

No study has investigated the relationship between bicuspid aortic valve (BAV) and the citation number of published articles related to this issue. BAV disease may cause both aortic stenosis and regurgitation; therefore, it manifests as different symptoms. Aortic stenosis in patients with BAV exhibits ambiguous hemodynamic effects; moreover, it may remain asymptomatically until the effective orifice area is narrowed below 1.5-2 cm² (9-13). However, a valve replacement should be performed in high-risk patients with severe aortic stenosis because these patients rapidly become symptomatic. On the other hand, aortic regurgitation may occur primarily or as a consequence of BAV. Calcification, myxomatous degeneration, infective endocarditis, rheumatic fever, and some drugs (e.g., fenfluramine, phentermine) may also cause aortic regurgitation (13-17). This complex is identified as bicuspid aortic syndrome, and the treatment algorithms are developed according to guidelines (18-20).

In this study, we aimed to determine the 100 most cited articles on BAV and evaluate these studies according to authors' characteristics, the origin of countries, institutes, and the journals that have published these articles via the Institute for Scientific Information (ISI) Web of Science (WOS) search engine.

\section{MATERIAL and METHODS}

This study was conducted after ethical approval (number: 377-GOA 2018/03-09) was obtained and was performed using advanced mode of ISI WOS search engine. The words "TS=bicuspid or Tl=bicuspid" were searched, and articles published between 1975 and 2018 were included. The search was done on June 14, 2018. Consequently, the 100 most cited articles related to BAV that have been published in international journals were identified. The list was created to evalu-

\section{Main Points:}

- This is the first study analyzing BAV from bibliometric point of view. A majority of these studies have investigated BAV clinically.

- There was no difference observed between the continent of the first author and the annual citation number. Moreover, no difference was observed between the continent of the journal and the annual citation number.

- The articles that had been published after 2010 had remarkably higher citation number ( $p<.05)$; this was interpreted as an increase in interventional cardiology publications for BAV syndrome.

- We believe that the citation numbers of studies on innovative materials (e.g., sutureless, bioprosthesis valves, etc.) for aortic valve will constantly increase in the following years. ate the 100 most cited articles related to BAV in the literature. The first authors of each article were reviewed, and it was checked whether they were a part of another article in the same list. The overall and annual cite count and information about authors, articles, and journals were determined via WOS and PubMed. Letters to the Editor and case reports were excluded from the study.

\section{Statistical Analysis}

Statistical analyses were performed using the SPSS (IBM SPSS Corp.; Armonk, NY, USA) version 20.0 software. Categorical data are presented in absolute ( $n$ ) and relative (\%) frequencies. All data are expressed as the mean value \pm standard deviation. For the comparison of the groups, Kruskal Wallis and Mann-Whitney $U$ tests were performed. $P<.05$ was considered statistically significant in all statistical tests.

\section{RESULTS}

A total of 4,130 studies that have been published between 1975 and 2018 were found after a search using the keywords "TS=bicuspid or TI=bicuspid" in the WOS search engine. Among all the 100 most cited articles list, the most cited article had 2,00l citations and the less cited had 108 citations. We did not cite all the 100 articles because we have included them in the last citation. The information about the first authors of the 100 articles on BAV is shown in Table I.

The analysis of institutions of the corresponding authors is presented in Table 2.

The most cited article was written by Hoffman et al. (22). The article was titled "The Incidence of Congenital Heart Disease" and was published in the Journal of the American College of Cardiology in 2002. The first 3 journals where the 100 articles had been published were found to be Circulation (18\%), Journal of The American College of Cardiology (17\%), and Journal of Thoracic and Cardiovascular Surgery (II\%). In Table 3, citation numbers and mean values of the 100 articles are listed. When the researchers were investigated according to their nationality, the USA (56\%), Canada (17\%), and Germany (7\%) were listed on top. Moreover, $22 \%$ of the authors were non-European citizens. All the 100 articles had been published in journals indexed in the science citation index.

However, there was a significant relation between the publishing year and the mean annual citation number; in particular, the articles that had been published after 2010 had remarkably higher citation number $(p<.05)$. Type of the papers had a significant association with citation numbers and annual citation numbers; in particular, the Guideline-type articles had much more total citation and annual citation numbers $(p<.05)$. Articles written by non-surgeon authors had higher annual citation numbers than the articles in which the first author was a surgeon. In addition, there was a significant difference related to annual citation numbers among journals $(p<.05)$. For instance, USA- and UK-originated journals had remarkably higher annual citation numbers when study subjects were considered. Guideline-type articles also had significantly higher total and annual citation numbers $(p<.05)$. The characteristics of the 100 articles related to BAV are presented in Table 4. 
TABLE I. The first authors of the 100 most cited articles about BAV in the literature

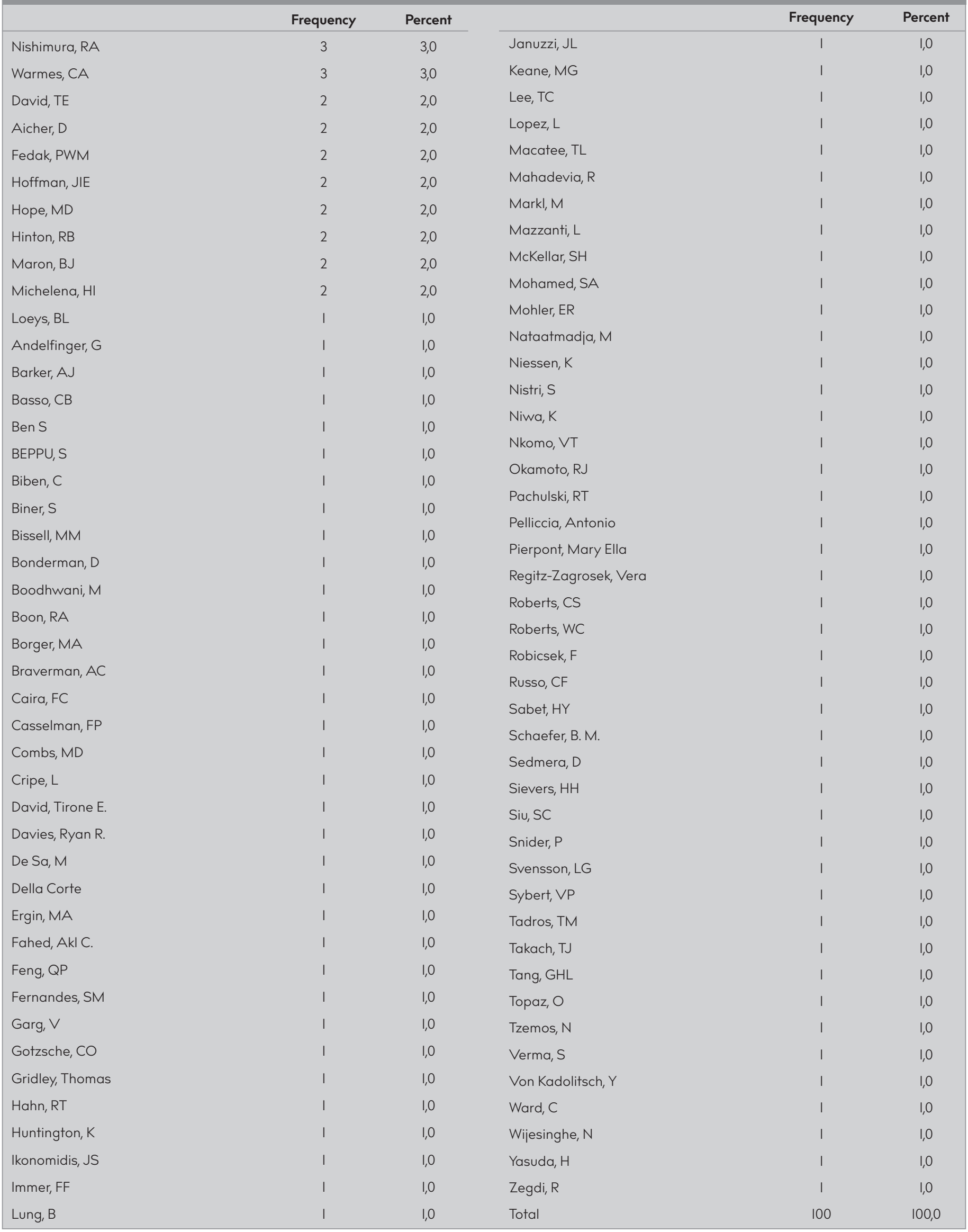




\section{TABLE 2. The institutes of the 100 most cited articles about BAV in the literature}

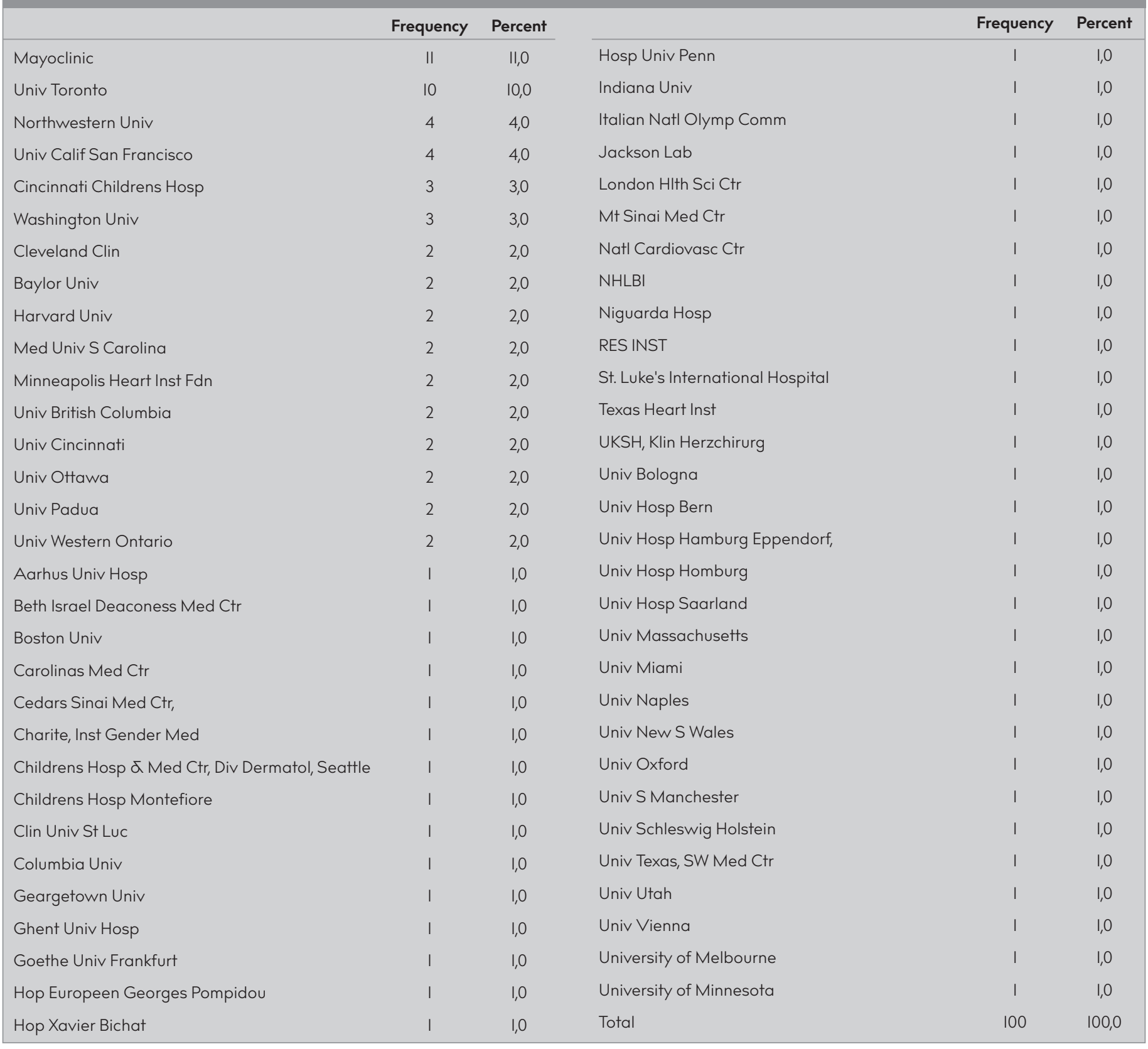

\section{DISCUSSION}

Owing to the development in intervention methods and new-generation aortic valves, indications in the guidelines and management are being updated consistently. However, contemporary studies are needed to obtain better knowledge about bicuspid aortic syndrome. This study is the first study analyzing BAV from bibliometric point of view. A majority of these studies have investigated BAV clinically. There was no difference observed between the continent of the first author and the annual citation number. Moreover, there was no difference between the continent of the journal and the annual citation number. The articles that had been published after 2010 had remarkably higher citation numbers $(p<.05)$; this was interpreted as an increase in interventional cardiology publications related to BAV syndrome.
Aortic stenosis is the most common valvular disease in developed countries (17-19). The underlying etiology may be a degenerative disease, BAV, or rheumatic cardiac disease. However, the etiology of BAV is still unclear (17). Early calcium deposit occurs; subsequently, genetic predisposition and BAV morphology lead to increased physical stress on the leaflets. Further studies may clarify the underlying mechanisms of this complex disease, delaying the progress at early stages. Abnormal valvular structure, turbulence, fibrosis, rigidity, and calcification lead to stenosis in valvular orifice; thus, valvular degeneration increases. BAV is the most common cause of congenital calcific aortic stenosis and is reported with a rate of $2 \%$ in the general population (I4). Progressive calcification often develops in the fifth and sixth decades, is more common in valve structure with single commissure, and has male dominance (19-22). However, it may coexist with an aneurysm related to medial degeneration. 
TABLE 3. Overall and mean annular citation numbers and the mean of the 100 most cited articles about BAV in the literature

Article

I The incidence of congenital heart disease Journal Of The American College Of Cardiology 2002; 39:1890-00.

22014 AHA/ACC Guideline for the Management of Patients With Valvular Heart Disease: Executive Summary.2014;63:2438-88

3 Mutations in NOTCHI cause aortic valve disease 437:270-74.

4 ACC/AHA 2008 Guidelines For The Management Of Adults With Congenital Heart Disease Journal Of The American College Of Cardıology 2008;23:EI-I2I .

5 The revised Ghent nosology for the Marfan syndrome journal Of Medıcal Genetıcs 2010;47:476-85.

6 ESC Guidelines on the management of cardiovascular diseases during pregnancy The Task Force on the Management of Cardiovascular Diseases during Pregnancy of the European Society of Cardiology (ESC) European Heart Journal 20II:32:3147-97.

72014 AHA/ACC Guideline for the Management of Patients With Valvular Heart Disease A Report of the American College of Cardiology/American Heart Association Task Force on Practice Guidelines Circulation 20|4;|29:EI2|-E643

8 ACC/AHA 2008 Guidelines for the Management of Adults With Congenital Heart Disease: A Report of the American College of Cardiology/American Heart Association Task Force on Practice Guidelines (Writing Committee to Develop Guidelines on the Management of Adults With Congenital Heart Disease): Developed in Collaboration With the American Society of Echocardiography, Heart Rhythm Society, International Society for Adult Congenital Heart Disease, Society for Cardiovascular Angiography and Interventions, and Society of Thoracic Surgeons Circulation. 2008;|I8:E7|4-

9 Genetic basis for congenital heart defects: Current knowledge - A scientific statement from the American heart association congenital cardiac defects committee, council on cardiovascular disease in the young Circulation 2007;115:3015-38

I0 Recommendations for Quantification Methods During the Performance of a Pediatric Echocardiogram: A Report From the Pediatric Measurements Writing Group of the American Society of Echocardiography Pediatric and Congenital Heart Disease Council journal Of The American Society Of Echocardıography.2010;23:465-95.

II Clinical and pathophysiological implications of a bicuspid aortic valve Circulation2002;106:900-4.

12 Clinical significance of the bicuspid aortic valve Heart 2000;83:81-85

13 Prevalence of congenital heart disease By: Hoffman, JIE; Kaplan, S; Liberthson, RR American Heart Journal 2004;147:425-39.

14 Frequency by decades of unicuspid, bicuspid, and tricuspid aortic valves in adults having isolated aortic valve replacement for aortic stenosis, with or without associated aortic regurgitation Circulation 2005; III:920-25

152014 AHA/ACC Guideline for the Management of Patients With Valvular Heart Disease: Executive Summary A Report of the American College of Cardiology/American Heart Association Task Force on Practice Guidelines Circulation20|4;129:2440-92

16 Bicuspid Aortic Valve Disease Journal Of The American College Of Cardiology2010;55:2789-2800

17 A classification system for the bicuspid aortic valve from 304 surgical specimens Journal Of Thoracıc And Cardıovascular Surgery2007;133:1226-33

18 Bicuspid aortic valve is heritable Journal Of The Amerıcan College Of Cardiology 2004;44:138-143

19 Aortic root dilatation in young men with normally functioning bicuspid aortic valves Heart1999;82:19-22.EART

Year
2002

Authors

Citation

number

Mean Annular

: Hoffman, JIE; Kaplan, S

1990

117.06

2014

Nishimura, Rick A.; Otto,

911

182.20

Catherine M.; Bonow,

Robert O; et al.

2005

Garg, $V_{;}$Muth, AN;

698

49,86

Ransom, JF; et al.

2008

Warnes, Carole A.;

Williams, Roberta G.;

Bashore, Thomas M.; Et Al.

2010 Loeys, Bart L.; Dietz, Harry C.; Braverman, Alan C.; et al.

Regitz-Zagrosek, Vera Lundqvist, Carina Blomstrom; Borghi, Claudio; et al.

2014 Nishimura, Rick A.; Otto Catherine M.; Bonow, Robert O.; et al.

2004,00 Warnes, Carole A.; Williams, Roberta G. Bashore, Thomas M. et al.

D. Woodrow, Jr; et al.

Lopez, Leo; Colan, Steven D.; Frommelt, Peter C.; et al.

Fedak, PWM; Verma $\mathrm{S}$; David, TE; et al.

Ward, C

Hoffman, JIE; Kaplan,

Siu, Samuel C:;

Silversides, Candice K.

2007 Sievers, Hans-H.;

Schmidtke, Claudia 
TABLE 3. Overall and mean annular citation numbers and the mean of the 100 most cited articles about BAV in the literature (Continued)

Article

20 Prevalence of sudden cardiac death during competitive sports activities in Minnesota high school athletes Journal Of The Amerıcan College Of Cardıology 1998;32:1881-84.

21 Structural abnormalities of great arterial walls in congenital heart disease Light and electron microscopic analyses Circulation 2001;103:393-400.

22 Association Of Aortıc Dilation With Regurgitant, Stenotıc And Functionally Normal Bicuspid Aortic Valves Journal Of The American College Of Cardıology 1992;19:283-88.

23 Incidence of Aortic Complications in Patients With Bicuspid Aortic Valves Journal Of The American Medical Associatıon 2011;306:1104-12.

24 Notch signaling in vascular development and physiology Development 2007:134:2709-18

25 Outcomes in adults with bicuspid aortic valves: Tzemos, Nikolaos; Therrien, Judith; Yip, James; et al. Journal Of The American Medical Association 2008;300:1317-25

26 Bicuspid aortic valves are associated with aortic dilatation out of proportion to coexistent valvular lesions Circulation2000;102:35-39.

27 Histologic abnormalities of the ascending aorta and pulmonary trunk in patients with bicuspid aortic valve disease: Clinical relevance to the Ross procedure Journal Of Thoracic And Cardıovascular Surgery1999;/I8:588-96.

28 Vascular matrix remodeling in patients with bicuspid aortic valve malformations: Implications for aortic dilatation Journal Of Thoracıc and Cardıovascular Surgery2003;126:797-806

29 The adult with congenital heart disease - Born to be bad? Journal Of The American College Of Cardıology2005;46:1-8

30 Dilation of the pulmonary autograft after the Ross procedure, LOUISIANA Date: APR 18-21, 1999 Sponsor(s): Amer Assoc Thorac Surg journal Of Thoracıc and Cardiovascular Surgery 2000;119:210-18

31 Cardiac septal and valvular dysmorphogenesis in mice heterozygous for mutations in the homeobox gene Nkx2-5 Circulation Research 2000;87:888-95

32 A comparison of outcomes of mitral valve repair for degenerative disease with posterior, anterior, and bileaflet prolapse Journal Of Thoracic and Cardiovascular Surgery 2005;130:1242-49

33 Ascending Aortic Dilatation Associated With Bicuspid Aortic Valve Pathophysiology, Molecular Biology, and Clinical Implications Circulation2009;119:880-90.

34 Should the ascending aorta be replaced more frequently in patients with bicuspid aortic valve disease? journal Of Thoracıc And Cardıovascular Surgery2004;128:677-83

35 Human degenerative valve disease is associated with up-regulation of low-density lipoprotein receptor-related protein 5 receptor-mediated bone formation journal Of The American College Of Cardıology 2006;47:1707-II

36 Bicuspid Aortic Valve: Four-dimensional MR Evaluation of Ascending Aortic Systolic Flow Patterns Radıology2010;255:53-61.

37 Natural history of asymptomatic patients with normally functioning or minimally dysfunctional bicuspid aortic valve in the community Circulation2008; I17:2776-84.

38 Extracellular matrix remodeling and organization in developing and diseased aortic valves Circulation Research 2006;98:1431-38.

39 Characterizing the young patient with aortic dissection: Results from the international registry of aortic dissection (IRAD) journal Of The American College Of Cardiology 2004;43:665-69. Volume: 43 Issue: 4 Pages: 665-669

40 Aortic dissection in pregnancy: Analysis of risk factors and outcome Annals Of Thoracic Surgery2003;76:309-14.
Year

1998

Authors

Maron, BJ; Ohman,

TE; Aeppli, D

2001

Niwa, K; Perloff, JK

Bhuta, SM; et al.

1992 Hahn, Rt; Roman, Mi;

Mogtader, Ah; et al.

Michelena, Hector I.; Khanna, Amber D:

Mahoney, Douglas; et al.

2007 Gridley, Thomas

275

citation number

umber

13,10

Tzemos, Nikolaos;

Keane, MG; Wiegers,

de Sa, M

Moshkovitz, Y;

Butany, J; et al.

2003 Fedak, PWM; de Sa,

MP; Verma, S; et al.

Klein, Michael D.

Shapira, Oz M.

2004 Borger, MA; Preston, M;

Ivanov, J; et al.

2006 Caira, FC; Stock

SR; Gleason, TG; et al.

2010 Hope, Michael D.; Hope,

Thomas A.; Meadows,

Alison $K_{\text {.; }}$ et al.

2008 Michelena, Hector I.; Desjardins, Valerie A.; Avierinos, Jean-

Francois; et al

2006,00 Hinton, RB; Lincoln, J; Deutsch, $\mathrm{GH}$; et al.

2004 Januzzi, JL; Isselbacher, 
TABLE 3. Overall and mean annular citation numbers and the mean of the 100 most cited articles about BAV in the literature (Continued)

Article

4l Congenitally bicuspid aortic valves: A surgical pathology study of 542 cases (1991 through 1996) and a literature review of 2,715 additional cases Mayo Clınıc Proceedıngs1999;74:14-26.

42 Heart Valve Development Regulatory Networks in Development and Disease Circulation Research;105:408-21.

43 Genetics of Congenital Heart Disease The Glass Half Empty Circulation Research2013;112:707-20.

44 Abnormal aortic valve development in mice lacking endothelial nitric oxide synthase. Circulation 2000;101:2345-48.

45 Mechanisms underlying aortic dilatation in congenital aortic valve malformation Circulation 1999;99:2138-43

46 The bicuspid aortic valve Current Problems In Cardıology 2005;30:470-522

47 The bicuspid aortic valve: an integrated phenotypic classification of leaflet morphology and aortic root shape Heart 2008;94:1634-38.

48 4D flow MRI: journal Of Magnetıc Resonance Imagıng 20I2;36:I0I5-36.

49 A prospective study to assess the frequency of familial clustering of congenital bicuspid aortic valve Journal Of The American College Of Cardıology 1997;30:1809-12

50 MicroRNA-29 in Aortic Dilation: Implications for Aneurysm Formation Circulation Research 2011;109:115-U66

5I Abnormal extracellular matrix protein transport associated with increased apoptosis of vascular smooth muscle cells in Marfan syndrome and bicuspid aortic valve thoracic aortic aneurysm Circulatıon2003;108:329-33.

52 Periostin is required for maturation and extracellular matrix stabilization of noncardiomyocyte lineages of the heart Circulation Research 2008;102:752-60.

53 Dissection Of The Aorta Associated With Congenital-Malformation Of The Aortıc-Valve Journal Of The American College Of Cardıology 1991;17:712-16.

54 Ablation of specific expression domains reveals discrete functions of ectoderm- and endoderm-derived FGF8 during cardiovascular and pharyngeal development Development 2003;130:6361-74.

55 The congenitally bicuspid aortic valve: How does it function? Why does it fail? Annals Of Thoracıc Surgery 2004;77:177-84.

56 Bicuspid Aortic Valve Is Associated With Altered Wall Shear Stress in the Ascending Aorta Circulation-Cardıovascular Imagıng 2012;5:457-66.

57 Epidemiology of valvular heart disease in the adult Nature Reviews Cardıology 2011;8:162-72.

58 Development And Progression Of Aortıc-Valve Stenosis - Atherosclerosis Risk-Factors - A Causal Relatıonshıp - A Clınıcal Morphological-Study Clınical Cardiologyl991;14:995-99.

59 Long-term results of aortic valve-sparing operations for aortic root aneurysm Journal Of Thoracic And Cardiovascular Surgery 2006;132:347-53.

60 Failure to prevent progressive dilation of ascending aorta by aortic valve replacement in patients with bicuspid aortic valve: comparison with tricuspid aortic valve Circulation 2003;108:291-94.

61 Anomalous Coronary-Arterıes - Angıographıc Findıngs In 80 Patients Internatıonal Journal Of Cardıology 1992;34:129-38.

Year

Authors

1999

\section{Sabet, HY; Edwards,}

WD; Tazelaar, HD; et al.

2009

Combs, Michelle D:; Yutzey, Katherine E.

2013 Fahed, Akl C; Gelb,

Bruce D; Seidman

J. G.; et al.

2000 Lee, TC; Zhao, YD: Courtman, DW; et al.

Bonderman, $D_{i}$ Gharehbaghi-Schnell, E; Wollenek, G; et al.

2005

Braverman, AC; Guven, $\mathrm{H}$; Beardslee, MA; et al

2008 Schaefer, B. M.; Lewin, M. B.; Stout, K. K.; et al.

2012 Markl, Michael Frydrychowicz, Alex Kozerke, Sebastian; et al.

1997 Huntington, K; Hunter, AGW; Chan, KL

20ll Boon, Reinier A.; Seeger, Timon; Heydt, Susanne; et al.

2003 Nataatmadja, M; West, M; West, J; et al.

Citation number

196 citation number 9,80

195 819,50 32,00

Snider, Paige; Hinton, Robert B.; MorenoRodriguez, Ricardo A.; et al.

Roberts, Cs; Roberts, Wc

Macatee, TL; Hammond, 166

Robicsek, F; Thubrikar,

Barker, Alex J.; Markl, Michael; Buerk, Jonas et al.

2011 lung, Bernard

Vahanian, Alec

Mohler, Er; Sherıdan, Mi; Nichols, R; et al.

Feindel, Christopher M.; Webb, Gary D.; et al

2003 Yasuda, H; Nakatani, S; Stugaard, M; et al. 
TABLE 3. Overall and mean annular citation numbers and the mean of the 100 most cited articles about BAV in the literature (Continued)

Article

62 Is it reasonable to treat all calcified stenotic aortic valves with a valved stent? Results from a human Anatomic study in adults Journal Of The American College Of Cardıology 2008;51:579-84.

63 Heart Valve Structure and Function in Development and Disease Annual Review Of Physıology 2011;73:29-46. VOL 73

64 Sinus of valsalva aneurysm or fistula: Management and outcome Annals Of Thoracıc Surgery 1999;68:1573-77.

65 Prevalence Of Cardiovascular Malformations And Association With Karyotypes In Turners-Syndrome Archives Of Disease In Childhood 1994;71:433-36.

66 Remodeling of chick embryonic ventricular myoarchitecture under experimentally changed loading conditions Anatomical Record 1999;254:238-52.

67 Task force 4: HCM and other cardiomyopathies, mitral valve prolapse, myocarditis, and Marfan syndrome Journal Of The Amerıcan College Of Cardiology 2005; 45:1340-45.

68 Natural history of ascending aortic aneurysms in the setting of an unreplaced bicuspid aortic valve Annals Of Thoracıc Surgery 2007;83:1338-44.

69 Development of heart failure and congenital septal defects in mice lacking endothelial nitric oxide synthase Circulatıon 2002;106:873-79.

70 Congenital heart disease in patients with Turner's syndrome Journal Of Pediatrics 1998;133:688-92.

71 Predictors of ascending aortic dilatation with bicuspid aortic valve: a wide spectrum of disease expression European Journal Of CardıoThoracic Surgery 2007;31:397-04.

72 An echocardiographic survey of primary school children for bicuspid aortic valve American Journal Of Cardıology 2004;93:661-63.

73 Congenital heart disease in patients with Turner's syndrome Journal Of Pedıatrıcs 1998;133:688-92.

74 Novel NOTCHI mutations in patients with bicuspid aortic valve disease and thoracic aortic aneurysms Journal Of Thoracıc And Cardıovascular Surgery 2007;134:290-96.

75 Cardiovascular malformations and complications in Turner syndrome Pediatrics 1998;10I:ell

76 Notch signaling in cardiac development Circulatıon Research 2008;102:1|69-|I8I.

$77 \mathrm{KCNJ} 2$ mutation results in Andersen syndrome with sex-specific cardiac and skeletal muscle phenotypes American Journal Of Human Genetics 2002;71:663-68.

78 Aortic Dilation in Bicuspid Aortic Valve Disease Flow Pattern Is a Major Contributor and Differs With Valve Fusion Type Circulatıon-Cardıovascular Imaging 2013;6:499-07.

79 Surgical treatment of the dilated ascending aorta: When and how? Annals Of Thoracic Surgery 1998;67:1834-39.

80 Aortıc-Aneurysm In Patıents With Functıonally Normal Or Mınımally Stenotıc Bicuspid Aortıc-Valve American Journal Of Cardıology 1991;67:781-82.

81 Aortic valve repair leads to a low incidence of valve-related complications European Journal Of Cardıo-Thoracıc Surgery 2010;37:127-132.

82 Repair-oriented classification of aortic insufficiency: Impact on surgical techniques and clinical outcomes journal Of Thoracıc And Cardıvascular Surgery 2009;137:286-94.

83 22qll.2 distal deletion: A recurrent genomic disorder distinct from DiGeorge syndrome and velocardiofacial syndrome American Journal Of Human Genetıcs 2008;82:214-21.

84 Evidence for efficacy of the Italian national pre-participation screening programme for identification of hypertrophic cardiomyopathy in competitive athletes European Heart Journal 2006;27:2196-200

Year Authors

Vlad; Noghin, Milena;

et al

201

Hinton, Robert B.; Yutzey,

Katherine E.

1999

Takach, TJ; Reul, GJ;

Duncan, JM; et al

Gotzsche, Co; Kragolsen, B; Nielsen, J; Et Al.

Sedmera, D; Pexieder, T; Rychterova, $\mathrm{V}_{\text {; }}$ et al.

Maron, BJ; Ackerman, MJ; 146 Nishimura, RA; et al.

Davies, Ryan R.; Kaple,

Divakar; et al.

2002

Feng, QP; Song, W;

$\mathrm{Lu}, \mathrm{XR}$; et al

Mazzanti, L; Cacciari, E

Della Corte, Alessandro

Bancone, Ciro; Quarto,

Cesare; et al

200

Basso, C; Boschello, Mi

Perrone, $\mathrm{C}$; et al

Mazzanti, L; Cacciari, E

McKellar, Stephen $\mathrm{H}_{\text {.; }}$. Tester, David J.; Yagubyan, Marineh; et al.

Niessen, Kyle; Karsan, Aly

Andelfinger, G; Tapper,

Bissell, Malenka M.; Hess,

Luca; et al.

1999

Ergin, MA; Spielvogel, D;

Apaydin, $A$; et al

199

Pachulskı, Rt; Weınberg,

$\mathrm{Al}$; Chan, $\mathrm{KI}$

2010

Aicher, Diana; Fries,

Svetlana; et al.

2009 Boodhwani, Munir; de

Kerchove, Laurent;

Glineur, David; et al.

2008 Ben-Shachar, Shay; Ou Zhishuo; Shaw, Chad A.; et al. 
TABLE 3. Overall and mean annular citation numbers and the mean of the 100 most cited articles about BAV in the literature (Continued)



Recently, bibliometric studies have been conducted in several fields of medicine worldwide. These studies may be based on both medical and surgical fields consequently. These studies investigating citation indexes and impact factors of previously published articles may also be seen in journals. The most commonly used parameters to evaluate the impact of a study are annual citation numbers. However, more cited articles are identified to be more scientific. These parameters also have limitations. The ISI is a USA-based scientific research association. The main functions of the ISI are to determine the candidate journals for indexing and to control them regularly. Nowadays, the ISI does not index all scientific journals because the journals have to meet the specified criteria. Nonetheless, the ISI serves as a citation and index database search engine, and this service contains published scientific papers since 1945. In addition, it is possible to access some valuable information such as personal, mean, and annular citation statistics via the WOS search engine (I-I0). (ISI= Instute of scientific information. WOS=web of science is an online subscription-based scientific citation indexing service orginally produced by the scientific information institude (ISI) in 1964.)

In a study by Ohba et al. (4), including the 100 most cited articles on optics, it was determined that these articles have mostly been published in the Archives of Ophthalmology, Ophthalmology, and American Journal of Ophthalmology. Yoon et al (II) listed the most cited articles regarding radiology between 1945 and 2012; these articles were divided into 4 groups according to neuroradiology, interventional, hepatic cancers, and breast imaging. In another study conducted in 2000, articles regarding anesthesiology have been published in the journals of Sweden, Norway, Finland, and the UK for 2 decades. In this 


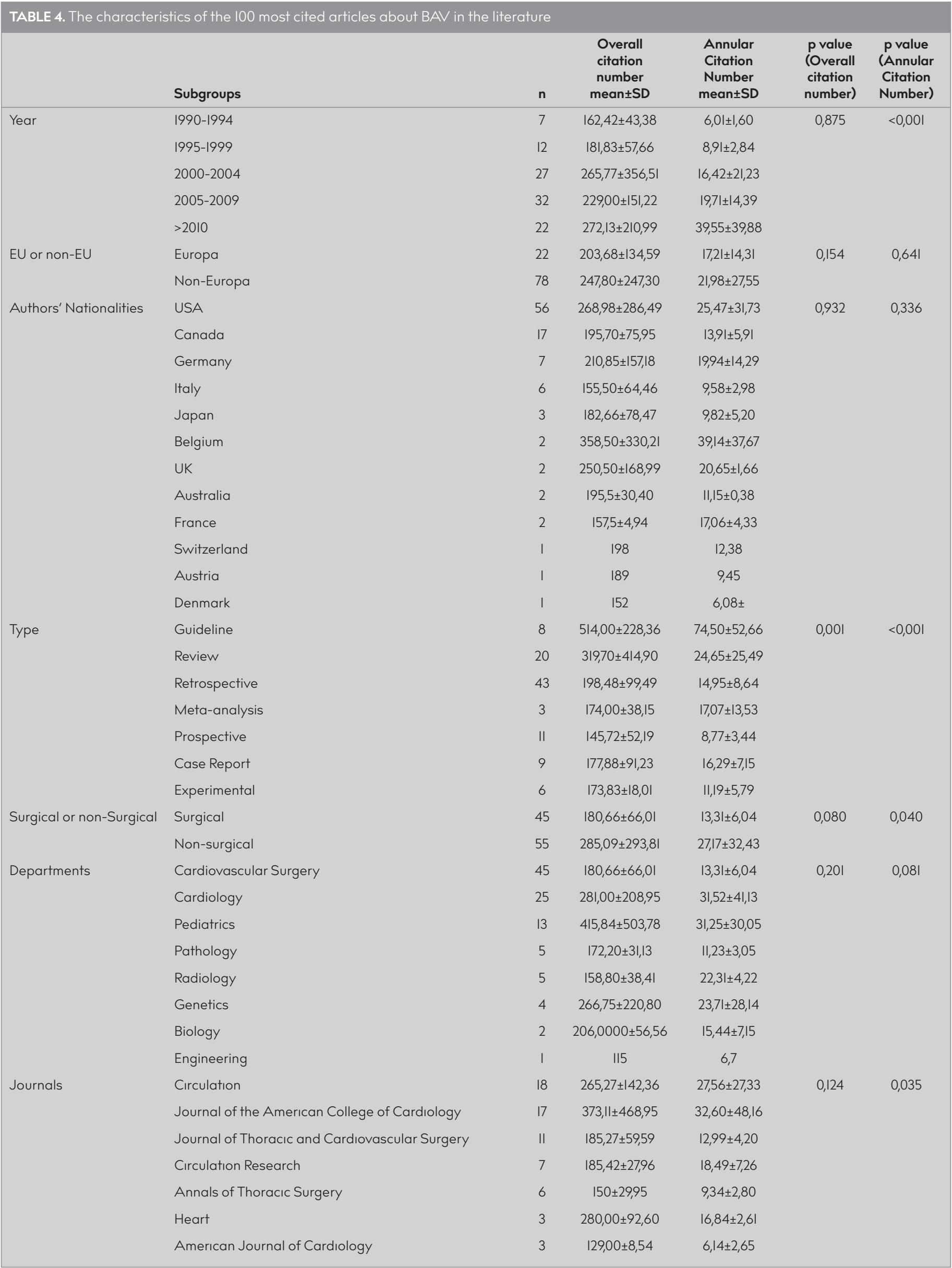




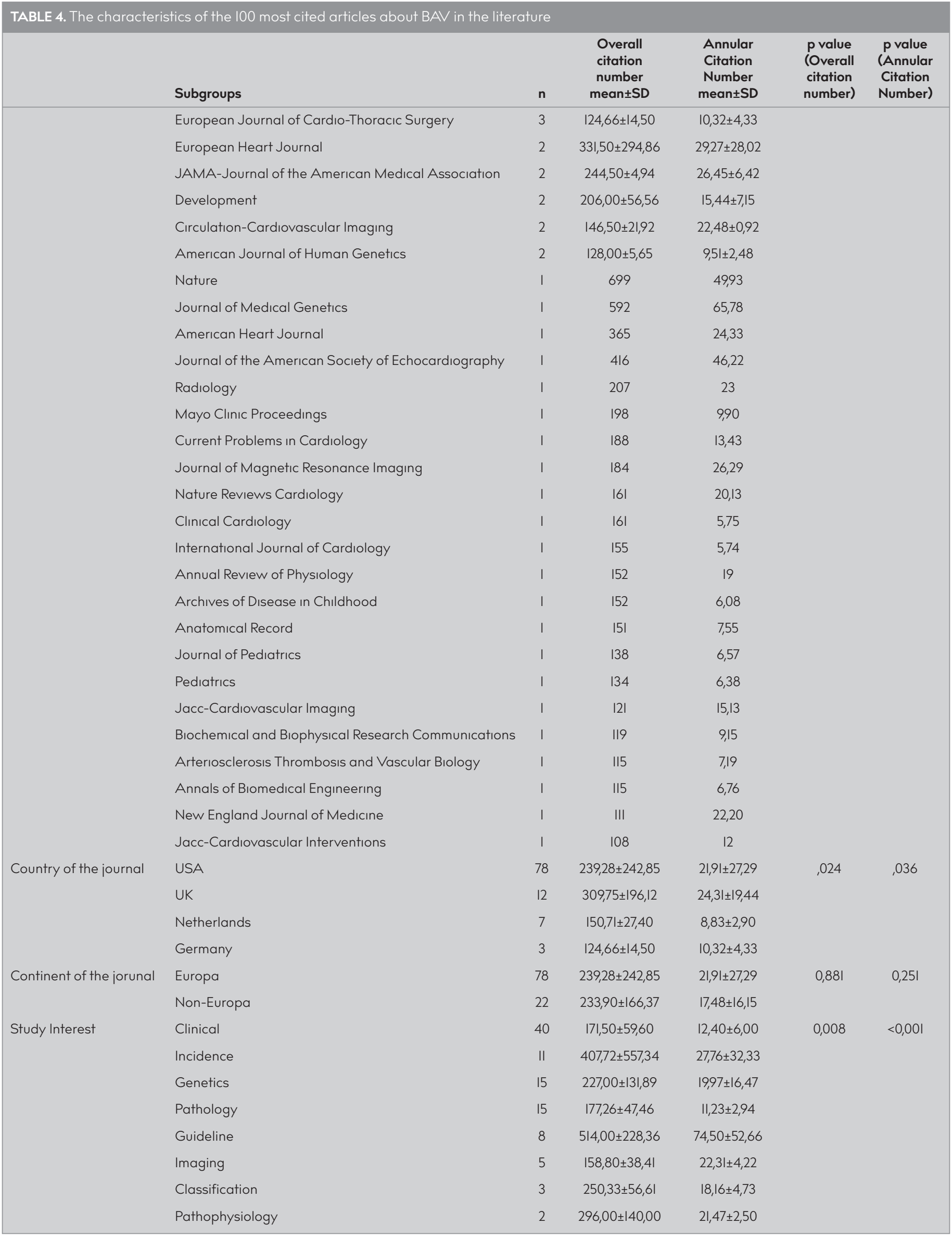


study, journals from Finland and Norway had significantly increased citation numbers within years. Furthermore, the percentage of the citation number also increased in journals from all these countries.

Bibliographic evaluation-based studies have become widespread in the cardiovascular field. Kolkailah et al. (23) presented a bibliographic study on behalf of the $50^{\text {th }}$ anniversary of heart transplantation. In this study, there was no correlation between the journal citation index and the yearly issue number. Usman et al. (24) assessed the 100 most cited articles related to valvular diseases and remarked that the number of interventional studies had increased recently. Compatible with this, we observed that studies on interventional valve placement and valve repair techniques have constantly increased in terms of number and citation. We interpreted these findings as a result of the popularity of the newly emerging interventional and valve spearing methods. On the other hand, Lai et al. (25) presented bibliographic research on aortic dissection and presented a historical development of surgical techniques. Liao et al. (26) evaluated the 100 most cited articles related to coronary artery diseases and remarked on the development in treatment options. Shuaib et al. (27) observed a decrease in the non-invasive cardiology field when compared with similar studies on cardiovascular diseases. They explained that these results were a consequence of improved bridging with revascularization methods, and the guidelines supported this. Considering our findings regarding the increased citation number of the studies about intervention methods, we concluded a similar comment, and we attributed this to a collaboration of clinicians as a heart team. Pennel et al. (28) observed an increase in citation number in the last 5 years when they evaluated the 100 most frequently cited articles related to cardiovascular magnetic resonance imaging (MRI). They attributed this finding to the increased patient population with cardiovascular diseases and the use of MRI. Oh et al. (29) conducted a bibliographical study on hypertension, and they detected an increased citation number in correlation with developing technologies and highlighted this acceleration.

\section{Study Limitations}

This study has several limitations. First, the most cited articles were determined via WOS and PubMed. Moreover, it is known that citation numbers may vary among different databases. Although these studies have evaluated overall and annular citation numbers, the list had not been formed in this manner. Second, although the overall citation number and annular citation rates have received broad acceptance in terms of evaluation of a scientific paper, a value of an article cannot be assessed only by the aforementioned parameters.

To the best of our knowledge, no study has evaluated BAV and the citation numbers of articles related to this subject in the literature. This study includes detailed information about the 100 most cited articles on BAV and presents their assessment. Consequently, we believe that the citation numbers of studies on innovative materials (e.g., sutureless, bioprosthesis valves, etc.) for aortic valve will constantly increase in the following years. Bibliographic articles using scientific search engines may contribute to determining the subjects that should be focused on in cardiovascular surgery. Furthermore, such studies should be updated regularly for reliable data analysis.
Ethics Committee Approval: Ethics committee approval was received for this study from the 9 Eylül University Faculty (number: 377-GOA 2018/03-09).

\section{Informed Consent: N/A}

Peer-review: Externally peer-reviewed.

Author contributions: Concept - S.B., V.H., T.G.; Design - S.B., V.H., S.B., C.B.; Supervision - V.H., S.B., G.A.; Resource - S.B., V.H., S.B., T.G., G.A.; Materials - S.B., G.A., S.B.; Data Collection and/or Processing - S.B.; Analysis and/or Interpretation - S.B., C.B., G.A., V.H., T.G.; Literature Search - S.B.; Writing - S.B., T.G., V.H.; Critical Reviews - S.B., V.H., S.B.

Conflict of Interest: Authors have no conflicts of interest to declare.

Financial Disclosure: The authors declared that this study has received no financial support.

\section{REFERENCES}

I. Ahmad SS, Ahmad SS, Kohl S, Ahmad S, Ahmed AR. The hundred most cited articles in bariatric surgery. Obes Surg 2015; 25(5): 900-9. [Crossref]

2. Paladugu R, Schein M, Gardezi S, Wise L. One hundred citation classics in general surgical journals. World J Surg 2002; 26(9): 1099105. [Crossref]

3. Terajima K, Aneman A. Citation classics in anaesthesia and pain journals: a literature review in the era of the internet. Acta Anaesthesiol Scand 2003; 47(6): 655-63. [Crossref]

4. Ohba N, Nakao K. The IOI most frequently cited articles in ophthalmology journals froml850 to 1950. Arch Ophthalmol 2010; 128(12): 1610-7. [Crossref]

5. Garfield E. 100 citation classics from the journal of the American Medical Association. JAMA 1987; 257(I): 52-9. [Crossref]

6. Ohba N, Nakao K, Isashiki Y, Ohba A. The 100 most cited articles in ophthalmology journals. Arch Ophthalmol 2007; 125(7): 952-60. [Crossref]

7. Lefaivre KA, Shadgan B, O'Brien PJ. 100 most cited articles in orthopaedic surgery. Clin Orthop Relat Res 201l; 469(5): 1487-97. [Crossref]

8. Thomson Scientific ISI Web of Knowledge: http://scientific.thomson.com/webofknowledge.

9. Aminian A, Christopher R. Daigle, Stacy A. Citation classics: Top 50 cited articles in bariatric and metabolic surgery. Surgery for Obesity and Related Diseases 2014; I0(5): 898-905. [Crossref]

10. Bayramlar $\mathrm{H}$, Cakici O, Karadag R. The most frequently cited 100 Turkish articles in Ophthalmic literature. Medeniyet Medical Journal 2015; 30(I): I3-21. [Crossref]

II. Yoon DY, Yun EJ, Ku YJ, Baek S, Lim KJ, Seo YL, et al. Citation classics in radiology journals: the 100 top-cited articles. AJR Am J Roentgenol 2013; 20I(3): 47I-8I. [Crossref]

12. Skram U, Larsen B, Ingwersen P, Viby-Mogensen J. Scandinavian research in anaesthesiology 198I-2000: visibility and impact in EU and world context. Acta Anaesthesiol Scand 2004; 48(8): 1006-13. [Crossref]

13. Martin M, Lorca R, Rozado J, Alvarez-Cabo R, Calvo J, Pascual I, et al. Bicuspid aortic valve syndrome: a multidisciplinary approach for a complex entity. J Thoracic Disease 2017; 9(6): 454-64. [Crossref]

14. Sabet HY, Edwards WD, Tazelaar HD, Daly RC. Congenitally bicuspit aortic valves: a pathology study of 542 cases and literature review of 2715 additional cases. Mayo Clin Proc 1999; 74: 14-26. [Crossref]

15. Longobardo L, Jain R, Carerii S, Zito C, Khandheria BK. Bicuspit Aortic Valve: Unlocking the Morphogenetic Puzzle. Am J Med 20l6; 129(8): 796-805. [Crossref]

16. Michelena HI, Khanna AD, Mahoney E, Margaryan E, Topilsky Y, Suri $\mathrm{RM}$, et al. Incidence of Aortic Complications in patients with bicuspid aortic valves. JAMA 20II; 306(I0): II04-12. [Crossref] 
17. Thannassoulis G, Yip JW, Filion K, Jamorski M, Webb G, Siu SC, et al. Retrospective study to identify predictors of the presence and rapid progression of aortic dilatation in patients with bicuspid aortic valves. Nat Clin Pract Cardiovasc Med 2008; 5(I2): 82I-8. [Crossref]

18. Lee TC, Zhao YD, Courtman DW, Stewart DJ. Abnormal aortic valve development in mice lacking endothelial nitric oxide synthase. Circulation 2000; I0I(20): 2345-8. [Crossref]

19. Qu XK, Quu XB, Yuan F, Wang J, Zhao CM, Liu XY, et al. Anovel NKX2.5 loss of function mutation associated with congenital bicuspid aortic valve. Am J Cardiol 2014; ||4(12): 189|-5. [Crossref]

20. Phillippi J, Green B, Eskay M, Kotlarczyk MP, Hill MR, Robertson AM, et al. Mechanism of aortic medial matrix remodeling is distinct in patients with bicuspid aortic valve. J Thorac Cardiovasc Surg 2014; 147(3): 1056-64. [Crossref]

21. Eqbe AC, Padang R, Brown RD, Khan AR, Luis SA, Huston J, et al. Prevalence and predictors of intracranial aneurysms in patients with bicuspid aortic valve. Heart 2017: 103(19): 1508-14.

22. Hoffman JIE, Kaplan S. The incidence of congenital heart disease. J Am Coll Cardiol 2002; 39(12): 1890-900. [Crossref]
23. Kolkailah AA, Fugar S, Vondee N, Hirii SA, Okoh AK, Ayoub A, et al. Bibliometric Analysis of the Top 100 Most Cited Articles in the First 50 Years of Heart Transplantation. Am J Cardiol 2018; 09 pii: S0002-9149(I8)3183I-9.

24. Usman MS, Siddiqi TJ, Khan MS, Fatima K, Butler J, Manning WJ, et al. A Scientific Analysis of the 100 Citation Classics of Valvular Heart Disease. Am J Cardiol 2017; 120(8): 1440-9. [Crossref]

25. Lai $\mathrm{P}$, Liu $Y H, X$ ue JH, He PC, Qiu YQ. The 100 most-cited articles on aortic dissection. BMC Cardiovasc Disord 2017; 17(I): 30. [Crossref]

26. Liao J, Wang J, Liu Y, Li J, He Q, Jiang W, et al. The most cited articles in coronary heart disease: A bibliometric analysis between 1970 and 2015. Int J Cardiol 2016; 222: 1049-52. [Crossref]

27. Shuaib W, Khan MS, Shahid H, Valdes EA, Alweis R. Bibliometric analysis of the top 100 cited cardiovascular articles. Am J Cardiol 2015; II5(7): 972-8I. [Crossref]

28. Pennell DJ, Baksi AJ, Kilner PJ, Mohiaddin RH, Prasad SK, Alpendurada F, et al. Review of Journal of Cardiovascular Magnetic Resonance 2013. J Cardiovasc Magn Reson 2014; 16: 100. [Crossref]

29. Oh YS, Galis ZS. Anatomy of success: the top 100 cited scientific reports focused on hypertension research. Hypertension 2014; 63(4): 64l-7. [Crossref] 